\title{
Phosphate removal from aqueous solutions using raw and activated red mud and fly ash
}

\author{
Yanzhong $\mathrm{Li}^{\mathrm{a}}$, Changjun Liu ${ }^{\mathrm{b}}$, Zhaokun Luan ${ }^{\mathrm{a}, *}$, Xianjia Peng ${ }^{\mathrm{a}}$, Chunlei Zhu ${ }^{\mathrm{a}}$, \\ Zhaoyang Chen ${ }^{\mathrm{a}}$, Zhongguo Zhang ${ }^{\mathrm{a}}$, Jinghua Fan ${ }^{\mathrm{a}}$, Zhiping Jia ${ }^{\mathrm{a}}$ \\ a State Key Laboratory of Environmental Aquatic Chemistry, Research Center for Eco-Environmental Sciences, \\ Chinese Academy of Sciences, P.O. Box 2871, Beijing 100085, PR China \\ ${ }^{\mathrm{b}}$ Shandong Aluminium Co. Ltd., Shandong 255061, PR China
}

Received 18 August 2005; received in revised form 23 November 2005; accepted 13 February 2006

Available online 6 March 2006

\begin{abstract}
The effect of acidification and heat treatment of raw red mud (RM) and fly ash (FA) on the sorption of phosphate was studied in parallel experiments. The result shows that a higher efficiency of phosphate removal was acquired by the activated samples than by the raw ones. The sample prepared by using the RM stirred with $0.25 \mathrm{M} \mathrm{HCl}$ for $2 \mathrm{~h}$ (RM0.25), as well as another sample prepared by heating the $\mathrm{RM}$ at $700{ }^{\circ} \mathrm{C}$ for $2 \mathrm{~h}$ (RM700), registered the maximum removal of phosphate (99\% removal of phosphate). This occurred when they were used in the phosphate sorption studies conducted at $\mathrm{pH} 7.0$ and $25^{\circ} \mathrm{C}$ with the initial $\mathrm{PO}_{4}{ }^{3-}$ concentration of $155 \mathrm{mg} \mathrm{P} / \mathrm{l}$. The FA samples treated in the same way described above can achieve 7.0 and $8.2 \mathrm{mg} \mathrm{P/l}$ phosphate removal for FA0.25 and FA700 respectively, corresponding to $45.2 \%$ and $52.9 \%$ removal. The activated materials performed higher phosphate removal over broader $\mathrm{pH}$ range compared with the raw ones. The influences of various factors, such as initial $\mathrm{pH}$ and initial phosphate concentration on the sorption capacity were also studied in batch equilibration technique. Solution pH significantly influenced the sorption. Each sample achieved the maximal removal of phosphate at pH 7.0. The amount of phosphate removal increased with the solute concentration. The Freundlich and Langmuir models were used to simulate the sorption equilibrium. The results indicate that the Langmuir model has a better correlation with the experimental data than the Freundlich model.
\end{abstract}

(C) 2006 Elsevier B.V. All rights reserved.

Keywords: Red mud; Fly ash; Phosphate; Sorption; Wastewater

\section{Introduction}

Excess phosphate presents in wastewater is one of the main causes of eutrophication that affects many natural water bodies. Many methods have been developed to remove excessive phosphate from water. The biological method is low-cost but the variability in chemical composition and temperature of wastewater would make the implementation of this process not feasible for wastewater treatment. Chemical treatment is widely used for phosphate removal. Chemicals such as lime, alum, and ferric chloride are the common precipitants used for phosphate removal [1] but their cost and sludge productions make chemical treatment an unattractive option for wastewater treatments.

\footnotetext{
* Corresponding author. Tel.: +8610 6284 9150; fax: +861062849198.

E-mail addresses: liyanzhongbj@yahoo.com.cn (Y. Li), Luanzk@mail.rcees.ac.cn (Z. Luan).
}

Sorption method can remove phosphate steadily. If the adsorption system is designed correctly it will produce a high-quality treated effluent. Most commercial systems currently use activated carbon as sorbent to remove dyes in wastewater because of its excellent adsorption ability [2]. However, activated carbon remains an expensive material since its high cost, which restricted its widespread use. In recent years, considerable attention has been paid based on economic and environmental concerns to the study of using different types of low-cost sorbents such as alum sludge [3], red mud (RM) [4-6], fly ash (FA) [7] and other waste materials $[8,9]$ as alternative adsorbents for sorption of phosphate from water. Therefore, the sorbent with the best sorption capacity should be selected to satisfy both economic efficiency and convenience. In addition, it needs to be tolerant of the diverse $\mathrm{pH}$ of wastewater.

Red mud emerges as a waste by-product during the alkaline leaching of bauxite in the Bayer process, and causes serious envi- 
ronmental problems due to its high alkalinity and large amount. Owing to its high aluminum, iron, and calcium content, RM has been found to remove fluoride [10], hexavalent chromium [11], dyes [12], phosphate [4,13-14], $\mathrm{Cu}^{2+}, \mathrm{Zn}^{2+}, \mathrm{Ni}^{2+}$ and $\mathrm{Cd}^{2+}$ [5] from aqueous solution, and the seawater neutralized red mud can remove arsenate as well [15]. RM has some advantages over alternative phosphate removal methods in that it can simultaneously remove some other potentially hazardous trace elements to very low concentrations. Genç et al. [16] investigated the release of metal ions into the solution from red mud neutralized with seawater during arsenate sorption. The results indicated that only negligible quantities of the metal ions analyzed are released.

Fly ash is the major solid waste by-product from coal-fired power plants. The major mineral phases detected in the FA samples were: anhydrite, lime, calcite, quartz and feldspars. FA has been found to remove fluoride [17], PCBs [18], $\mathrm{Cu}^{2+}, \mathrm{Pb}^{2+}$ [19] and phenolic compounds [20] from aqueous solution [9]. One of the main advantages of phosphate removal by using FA and RM over the other chemical treatment methods is that adsorption has been shown to be an economically feasible alternative. Environmental and economic concerns have led to an ongoing research to find effective ways to utilize the abundant and easily available RM and FA [7]. Although fly ash was reported leaching heavy metals [21], leaching rates of metals from brown coal fly ash was reduced using inorganic polymer [22], and solidification/stabilization of arsenic containing solid wastes was achieved using portland cement, fly ash and polymeric materials [23]. The presence of various strongly active constituents in FA and RM also makes them one of the most suitable materials for phosphate sorption.

Many previous studies have been focused on the research of sorption properties of raw RM and FA. However, little research has been conducted to focus on improving the sorption capacity [24]. In addition, the activation process that influences sorption has not been very clear. Therefore, the RM and FA activated with different methods were used in this study in order to improve phosphate sorption capacity, recycle waste matters and reduce environmental pollution. The removal of phosphate from aqueous solution using the raw RM, FA and their active forms prepared by different chemical and thermal methods were studied in batch equilibration technique. Then the samples with higher efficiency of phosphate removal were studied in the further sorption experiments. The influences of initial $\mathrm{pH}$ and initial phosphate concentration on the sorption capacity were investigated. The isotherm sorption experiments were also conducted using the active materials.

\section{Materials and methods}

\subsection{Characterisation}

Sorption of phosphate was measured using the ascorbic acid method with a HACH DR/4000U spectrophotometer, according to APHA standard methods [25]. A pH meter (Orion) was used to measure the $\mathrm{pH}$ of the solutions. X-ray diffraction (XRD) patterns of all samples were obtained with a Rikaku Dmax-RB diffractometer using $\mathrm{Cu} \mathrm{K} \alpha$ radiation at $40 \mathrm{kV}$ and $150 \mathrm{~mA}$ over the range $(2 \theta)$ of $10-100^{\circ}$. The micrograph of the samples was determined using a $30 \mathrm{kV}$ scanning electron microscope (SEM) HITACHI S-3000N. The specific surface area of the samples was determined by the BET nitrogen gas sorption method using an accelerated surface area and porosimetry (ASAP2000) from Micromeritics Co., U.S.A.

All chemicals and reagents used were of analytical reagent grade. All glassware and sample bottles were soaked in diluted $\mathrm{HCl}$ solution for $12 \mathrm{~h}$, washed and then rinsed four times with deionised water. Deionised water was used for preparing solutions. All experiments were conducted in duplicate and the average values were used for data analysis.

\subsection{Materials}

The 100 mesh particle sized, washed, and air-dried RM and coal FA samples used in the present study were obtained from Shandong Aluminium Corporation, Shandong, China, and have the following average composition (wt.\%) listed in Table 1. Both the RM and FA were activated with acid and thermal treatment, respectively, their composition also listed in Table 1. The composition of red mud samples and fly ash samples are quite different, which resulted in the different efficiency of phosphate removal (Table 1). For example, the primary composition sequence of red mud samples is $\mathrm{CaO}>\mathrm{SiO}_{2}>\mathrm{Fe}_{2} \mathrm{O}_{3}>\mathrm{Al}_{2} \mathrm{O}_{3}$, while that of fly ash samples is $\mathrm{SiO}_{2}>\mathrm{Al}_{2} \mathrm{O}_{3}>\mathrm{Fe}_{2} \mathrm{O}_{3}>\mathrm{CaO}$.

\subsubsection{Acid activation of red mud and fly ash}

The acidification of the samples was carried out under atmospheric pressure in a jacketed glass reactor fitted with a thermometer, and a stirrer. The stirrer made of teflon had two blades. A constant temperature circulator was used to maintain the desired temperature in the reactor. A typical run was carried out at $25^{\circ} \mathrm{C}$ for $2 \mathrm{~h}$ as follows: specified amounts of hydrochloric acid of known concentrations $(0.001,0.01,0.05,0.25,0.5$, $1,2 \mathrm{~mol} / \mathrm{l} \mathrm{HCl}$ ) and the samples were loaded into the glass reactor (the ratio of liquid to solid was $20 \mathrm{ml} / \mathrm{g}$ ). The stirring speed was held constant by means of a digital controlled stirrer. At the end of the experiment, the content of the reactor was centrifuged for $10 \mathrm{~min}$ at $7000 \mathrm{rpm}$ in a refrigerating centrifuge. The residue was washed with distilled water and dried at $100{ }^{\circ} \mathrm{C}$ overnight.

\subsubsection{Heat activation of red mud and fly ash}

Batches of dry sample placed in porcelain dishes were heattreated at various temperatures $(200,500,600,700,800,900$ and $1000^{\circ} \mathrm{C}$ ) for various amounts of time ( $30 \mathrm{~min}, 1$ and $2 \mathrm{~h}$ ) in an oven. The powder was stirred at $30 \mathrm{~min}$ intervals during the heat treatment. At the end of the treatment, the powder was ground in a mortar and sieved through a 100 mesh sieve.

\subsection{Sorption studies}

Sorption studies were carried out by shaking $20 \mathrm{ml}$ of $155 \mathrm{mg} / 1 \mathrm{KH}_{2} \mathrm{PO}_{4}$ (as P) solution at $180 \mathrm{rpm}$ with $0.1 \mathrm{~g}$ of sor- 
Table 1

Composition and properties of RM, FA, activated red mud and fly ash (wt.\%)

\begin{tabular}{|c|c|c|c|c|c|c|}
\hline Composition & RM & RM0.25 & RM700 & FA & FA0.25 & FA700 \\
\hline $\mathrm{SiO}_{2}$ & 19.14 & 20.34 & 22.45 & 56.38 & 56.75 & 57.20 \\
\hline $\mathrm{Fe}_{2} \mathrm{O}_{3}$ & 12.76 & 14.84 & 13.05 & 7.35 & 7.02 & 6.09 \\
\hline $\mathrm{Al}_{2} \mathrm{O}_{3}$ & 6.93 & 7.20 & 8.06 & 25.36 & 27.10 & 28.47 \\
\hline $\mathrm{MgO}$ & 1.15 & 1.42 & 1.14 & 1.45 & 1.85 & 1.57 \\
\hline $\mathrm{TiO}_{2}$ & 3.43 & 3.72 & 4.25 & - & - & - \\
\hline $\mathrm{K}_{2} \mathrm{O}$ & 1.20 & 0.83 & 0.64 & 0.40 & 0.37 & 0.32 \\
\hline Loss on ignition & 5.73 & 2.13 & 0.65 & 5.00 & 2.85 & 1.83 \\
\hline $\mathrm{pH}$ & 11.70 & 10.14 & 11.94 & 9.37 & 8.27 & 9.96 \\
\hline
\end{tabular}

bent in the bottles capped with glass screws for $4 \mathrm{~h}$ at $25^{\circ} \mathrm{C}$, and a background electrolyte of $0.01 \mathrm{M} \mathrm{KCl}$ was used as diluent for all batch experiments. After equilibrium, the samples were centrifuged at $5000 \mathrm{rpm}$ for $10 \mathrm{~min}$ and a clear aliquot of the supernatant was taken and analyzed for phosphate spectrophotometrically. The amount of phosphate adsorbed per unit of adsorbents $(X)$ was calculated by

$X=\frac{\left(C_{\mathrm{i}}-C_{\mathrm{e}}\right) V}{m}$,

where $X$ is the concentration of the phosphate adsorbed, $C_{\mathrm{i}}$ and $C_{\mathrm{e}}$ are the initial and final concentrations of the phosphate in solution, respectively, $V$ is the solution volume, and $m$ is the mass of sorbent. Blank runs, with only the sorbents in $20 \mathrm{ml}$ of $0.01 \mathrm{M} \mathrm{KCl}$ solution, were conducted simultaneously under identical conditions to account for phosphate removed by the sorbent or adsorbed by the glass container.

\subsubsection{Effect of time on the removal of phosphate}

The effect of time on the removal of phosphate was investigated as described in sorption studies (Section 2.3) for increasing periods of time, until equilibrium was achieved.

\subsubsection{Batch $p H$ studies}

The procedure for batch $\mathrm{pH}$ studies was similar to sorption studies procedure (Section 2.3). The $\mathrm{pH}$ of the medium varied from 1.0 to 11.0 , and $1 \mathrm{~N} \mathrm{HC} 1$ or $1 \mathrm{~N} \mathrm{NaOH}$ was used for $\mathrm{pH}$ adjustment. Before analysis, samples were centrifuged at $5000 \mathrm{rpm}$ for $10 \mathrm{~min}$ and the supernatant fluid analyzed for the remaining phosphate. The study was performed at a constant temperature of $25^{\circ} \mathrm{C}$. Blanks were run simultaneously, without any sorbent, to determine the impact of $\mathrm{pH}$ change on the phosphate solutions.

\subsubsection{Sorption isotherms}

The sorption isotherm indicates the distribution of adsorbate molecules between the liquid phase and the solid phase when the sorption process reaches an equilibrium state. Solutions of different initial concentrations - 0.31, 3.1, 15.5, 155, 775, 1550, $3100 \mathrm{mg} / \mathrm{KH}_{2} \mathrm{PO}_{4}$ (as P) - were used to investigate the effect of concentration on the phosphate removal by $0.1 \mathrm{~g}$ of sorbent in $20 \mathrm{ml}$ of solution for $4 \mathrm{~h}$.

\section{Results and discussion}

\subsection{Effect of different treatments on the removal of phosphate}

The sorption capability of the materials was evaluated by carrying out sorption experiments after the activation process of the raw materials. The activated materials significantly enhanced the phosphate removal from aqueous solution. The active red mud showed remarkably higher removal of phosphate than the active fly ash did.

\subsubsection{Effect of heat treatment on the phosphate removal}

The results of the sorption studies showed a great reduction in the phosphate content of aqueous solution as a result of the active treatment with the RM and FA. The results obtained using the activated RM were particularly remarkable. Fig. 1 displayed that the phosphate removal from aqueous solution by the RM and FA activated thermally enhanced with increase of temperature and time listed in this study, and the experiments carried out in the original $\mathrm{pH}$ without acid or alkali control. The phos-

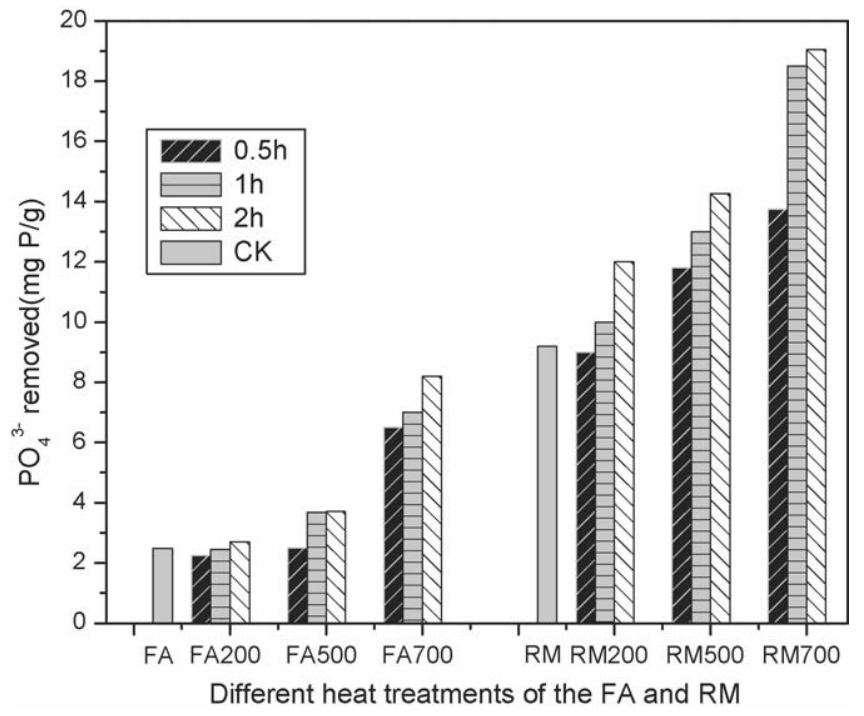

Fig. 1. Effect of different thermal treatments on the removal of phosphate ( $C_{0}=155 \mathrm{mg} \mathrm{P} / 1,25^{\circ} \mathrm{C}, \mathrm{CK}$ is the raw sample without treatment). 
phate removal by the RM calcined at $700^{\circ} \mathrm{C}$ for $2 \mathrm{~h}$ (RM700) achieved $19.05 \mathrm{mg} \mathrm{P} / \mathrm{g}$ when the initial phosphate concentration was $155 \mathrm{mg} \mathrm{P} / \mathrm{l}$, which performed better than those treated with other heat processes, especially that of the raw RM was only $9.19 \mathrm{mg} \mathrm{P} / \mathrm{g}$. However, the efficiency of phosphate removal did not always increase as time passed, and such removal did not increase as the temperature rose. According to our previous study, the phosphate removal by the red mud calcined at $200,500,600,800,900,1000^{\circ} \mathrm{C}$ for $2 \mathrm{~h}$ was $12,14.27,16.5$, $14.38,14.13,13.75 \mathrm{mg} \mathrm{P} / \mathrm{g}$. The effect of temperature on the phosphate removal by fly ash acted in the similar trend. This could be explained by the effect of temperature on water removal and sintering. During calcining at $500^{\circ} \mathrm{C}$, the surface area of RM is enlarged initially, as the expulsion of water leads to the development of porosity [26]. After this, the phosphate removal process is most efficient at $700{ }^{\circ} \mathrm{C}$ and then becomes less efficient as temperatures are increased or time is prolonged. This is because the decomposition of some hydroxyl groups, calcite and the sintering shrinkage of materials (Fig. 2). For FA, the peaks of calcite disappear in the treatment of calcinations and acid treatment (Fig. 3). Since the acid treatment can remove calcite and the FA calcined at $700{ }^{\circ} \mathrm{C}$ for $2 \mathrm{~h}$ (FA700) can result in the removal of some unburned carbon and the decomposition of calcite. The results of X-ray analysis in Figs. 2 and 3 reveal the presence of phosphate after sorption process. The FA700 removed $8.2 \mathrm{mg} \mathrm{P} / \mathrm{g}$ when the initial phosphate concentration was $155 \mathrm{mg} \mathrm{P} / \mathrm{l}$, but the raw FA only removed $2.49 \mathrm{mg} \mathrm{P} / \mathrm{g}$. The phosphate removal by the fly ash calcined at 200, 500, 600, $800,900,1000^{\circ} \mathrm{C}$ for $2 \mathrm{~h}$ was $2.70,3.70,4.81,6.59,3.02$, $2.45 \mathrm{mg} \mathrm{P} / \mathrm{g}$ in our previous study. In further experiments, the sorption properties of RM700 and FA700 were the study's focus when evaluating the effect of heat treatment on the RM and FA.

\subsubsection{Effect of acidification on the phosphate removal}

Acidification of the RM and FA enhanced the phosphate removal from aqueous solution when treated with dilute $\mathrm{HCl}$ (Fig. 4), and the sorption experiments carried out in the original $\mathrm{pH}$. The RM treated with $0.25 \mathrm{~mol} / \mathrm{l} \mathrm{HCl}$ for $2 \mathrm{~h}(\mathrm{RM} 0.25)$ had higher phosphate removal $(24.67 \mathrm{mg} \mathrm{P} / \mathrm{g})$ than those treated with $0.5,1$ and $2 \mathrm{~mol} / 1 \mathrm{HCl}(16.44,7.35,5.22 \mathrm{mg} \mathrm{P} / \mathrm{g}$, respectively). For the FA, the removal of phosphate with samples treated with $0.25,0.5,1$ and $2 \mathrm{~mol} / 1 \mathrm{HCl}$ was $7.01,2.62,1.52,1.48 \mathrm{mg} \mathrm{P} / \mathrm{g}$, respectively. In the further experiments, the samples prepared by treatment of the RM and FA with $0.25 \mathrm{~mol} / \mathrm{l} \mathrm{HCl}$ were considered primarily, referred to as RM0.25 and FA0.25. Samples treated with thick acid may cause a partial loss of acid-soluble fractions like hematite and calcite decrease in the residue, therefore the solubilized $\mathrm{Fe}$ and $\mathrm{Al}$ retained in the residue may play an important role in the removal of phosphate in aqueous solution. However, the RM and FA treated with dilute $\mathrm{HCl}$
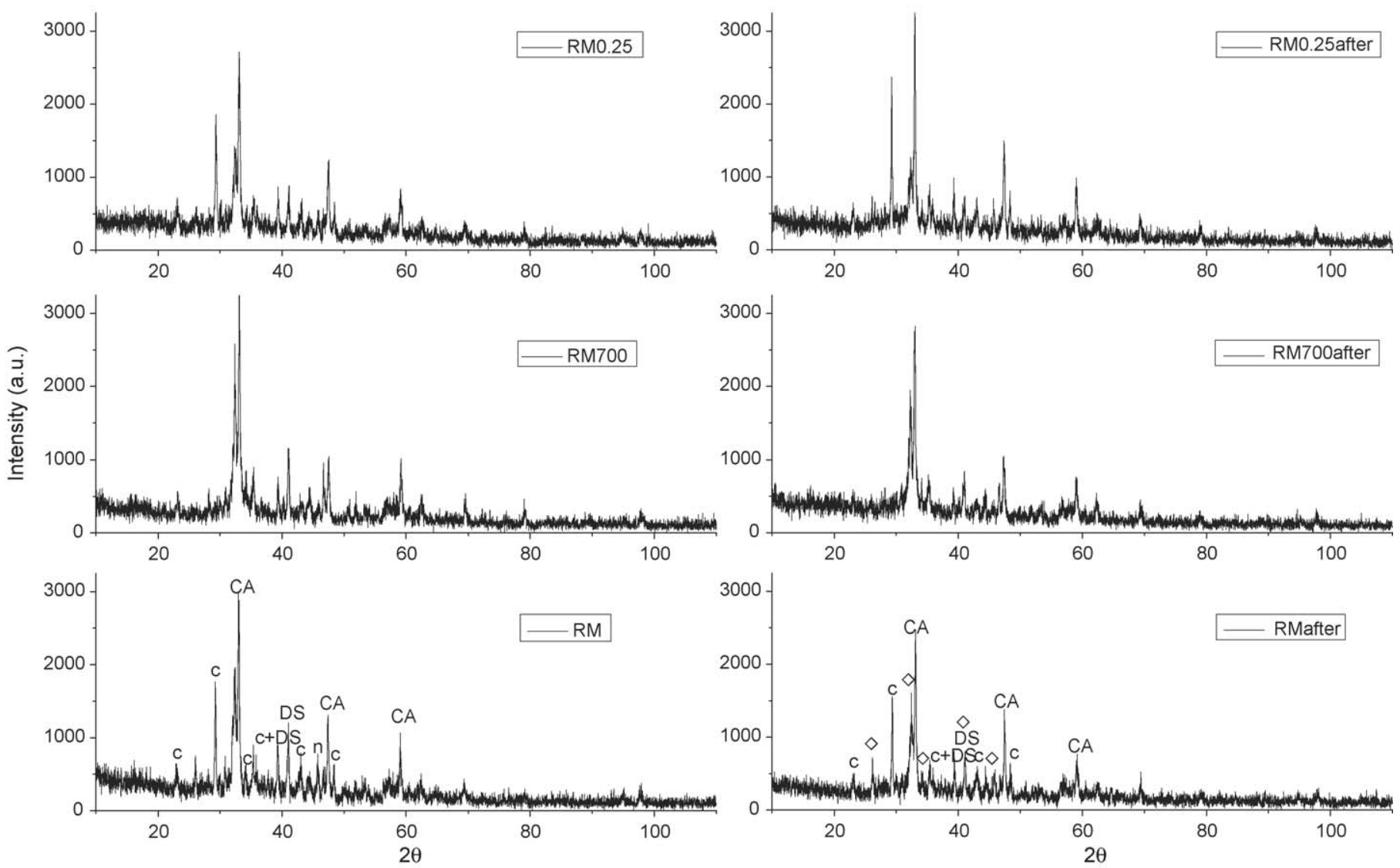

Fig. 2. XRD patterns of red mud. Symbol: CA: calcium aluminate; c: calcite; n: nepheline; DS: dicalcium silicate; phosphates are marked by rhombus $(\diamond)$ (sample: RM0.25: RM treated with $0.25 \mathrm{~mol} / \mathrm{l} \mathrm{HCl}$ for $2 \mathrm{~h}$; RM700: RM calcined at $700^{\circ} \mathrm{C}$ for $2 \mathrm{~h}$; RMafter, RM700after, RM0.25after represent the samples after phosphate adsorption using RM, RM700 and RM0.25, respectively). 

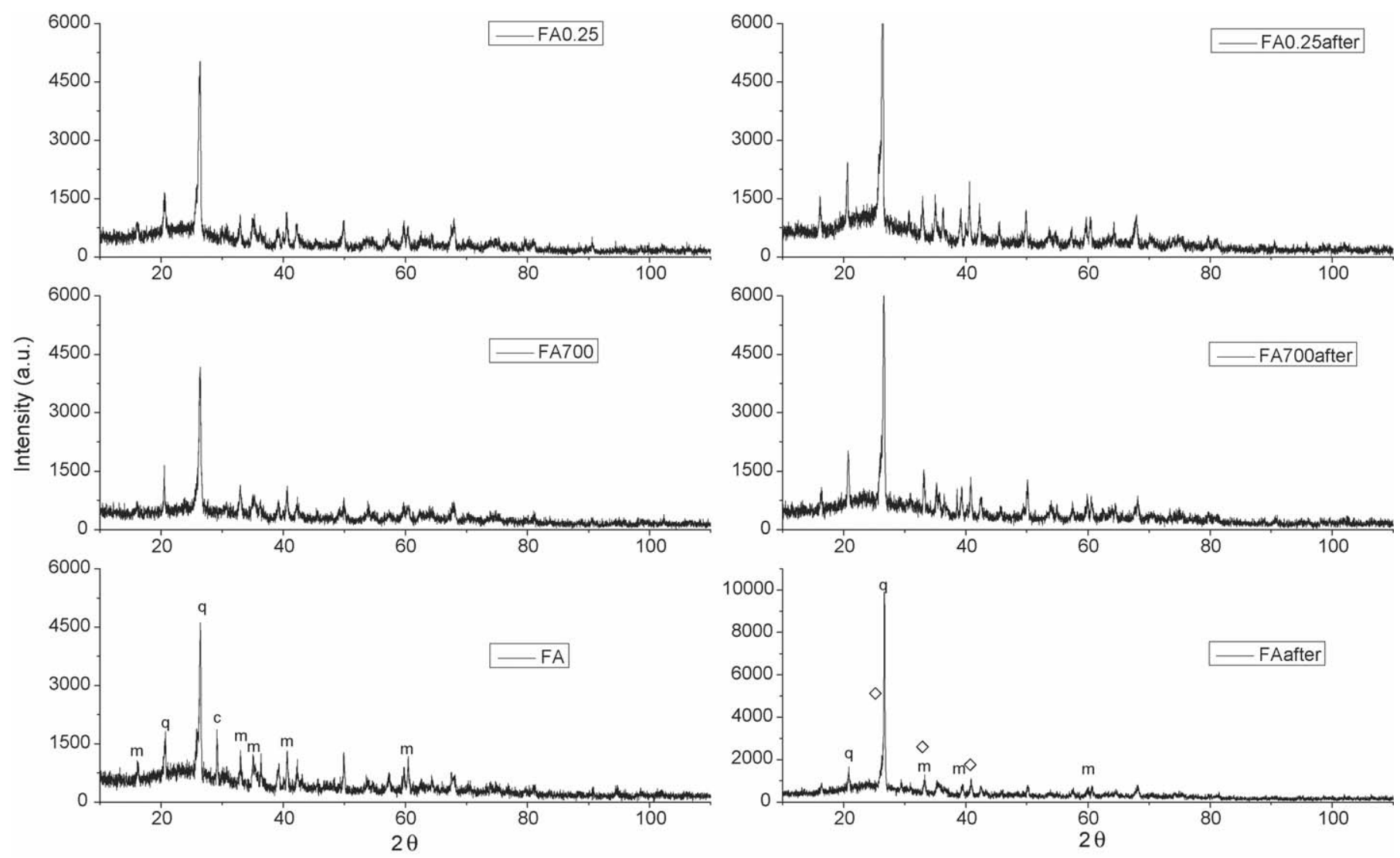

Fig. 3. XRD patterns of fly ash. Symbol: q: quartz; c: calcite; m: mullite; phosphates are marked by rhombus $(\diamond)$ (sample: FA0.25: FA treated with 0.25 mol/l HCl for $2 \mathrm{~h}$; FA 700: FA calcined at $700^{\circ} \mathrm{C}$ for $2 \mathrm{~h}$ ).

(0.001, 0.01, $0.05 \mathrm{~mol} / \mathrm{l})$ in our previous experiment did not achieve such high phosphate removal as the samples treated with $0.25 \mathrm{~mol} / \mathrm{l} \mathrm{HCl}$. For example, phosphate removal of the red mud treated with $0.001,0.01,0.05 \mathrm{~mol} / \mathrm{l} \mathrm{HCl}$ was $15.77,18.58$, $19.54 \mathrm{mg} \mathrm{P} / \mathrm{g}$, respectively, and that of the fly ash with the same treatments was $3.28,4.81,5.63 \mathrm{mg} \mathrm{P} / \mathrm{g}$, respectively. Wang et

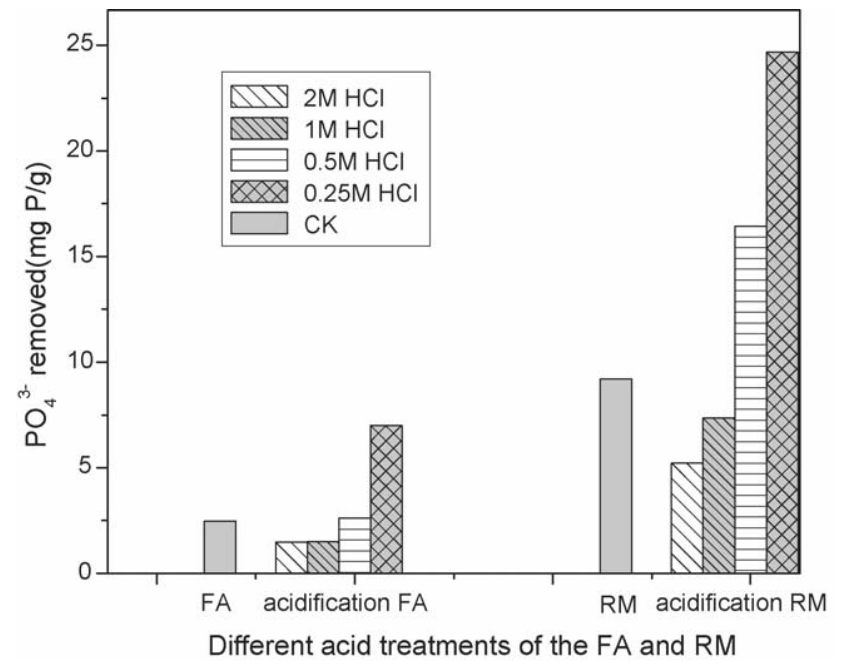

Fig. 4. Effect of different acid treatments on the removal of phosphate $\left(C_{0}=155 \mathrm{mg} \mathrm{P} / 1,25^{\circ} \mathrm{C}, \mathrm{CK}\right.$ is the raw sample without treatment). al. [12] indicated that the minerals in carbon can dissolve in acid treatment and thus the pore volume and surface area of the fly ash samples increase, resulting in an increase in sorption (Fig. 3).

SEM may provide visual evidence of the effect of dilute $\mathrm{HCl}$ on the RM and FA surface erosion and collapse. Calcium and some other acid-soluble salts were dissolved, some coarse exterior and new cavities appeared during the acidification process. The generation of new surface area by acidification was observed from the difference between the SEM of the samples raw and those exposed to $0.25 \mathrm{~mol} / \mathrm{l} \mathrm{HCl}$ (Fig. 5).

The results of specific surface area of the samples were listed in Table 2, which demonstrated that treatment with dilute $\mathrm{HCl}$ can improve the surface areas of the RM and FA samples (Fig. 5), and the phosphate removal enhanced as well (Fig. 1). Those sam-

Table 2

BET surface area of the raw and activated red mud and fly ash

\begin{tabular}{lc}
\hline Sample & $S_{\text {BET }}\left(\mathrm{m}^{2} / \mathrm{g}\right)$ \\
\hline RM & 14.09 \\
RM700 & 9.69 \\
RM0.25 & 19.35 \\
FA & 14.55 \\
FA700 & 12.20 \\
FA0.25 & 18.7 \\
\hline
\end{tabular}




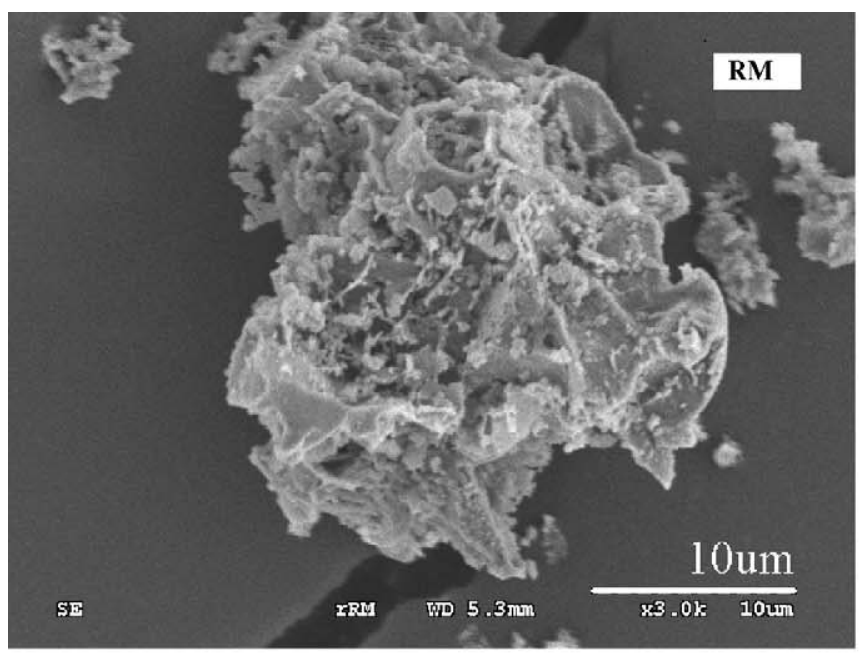

(a)

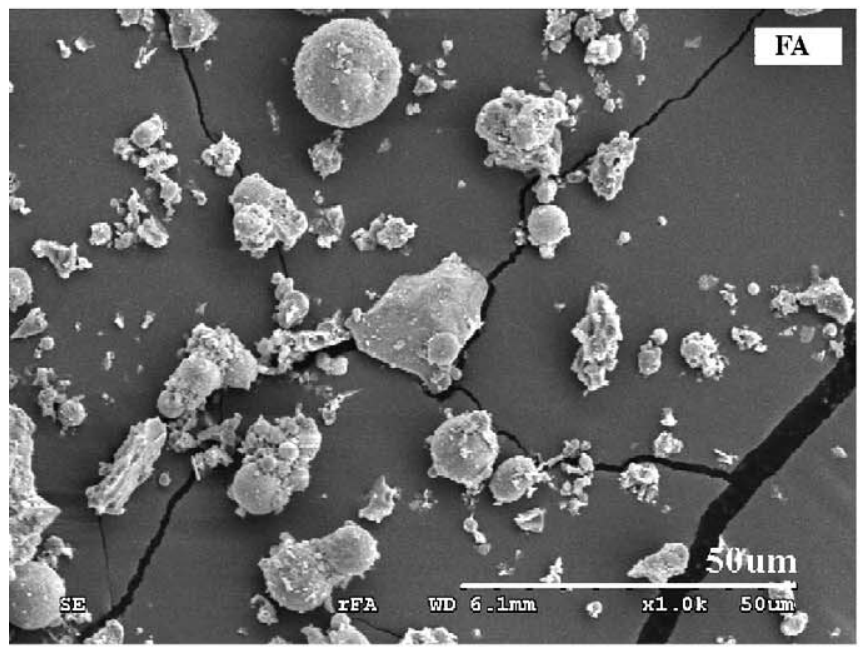

(c)

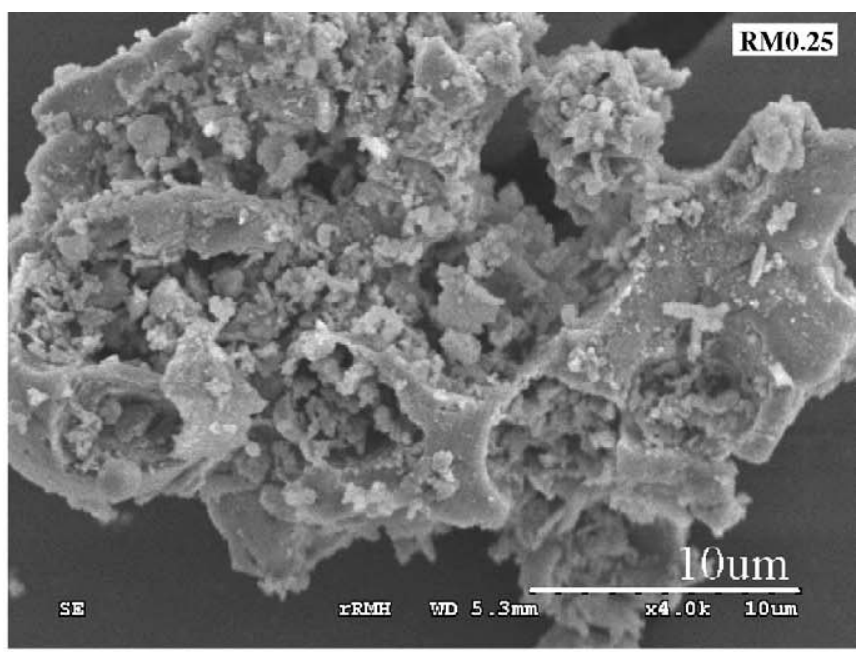

(b)

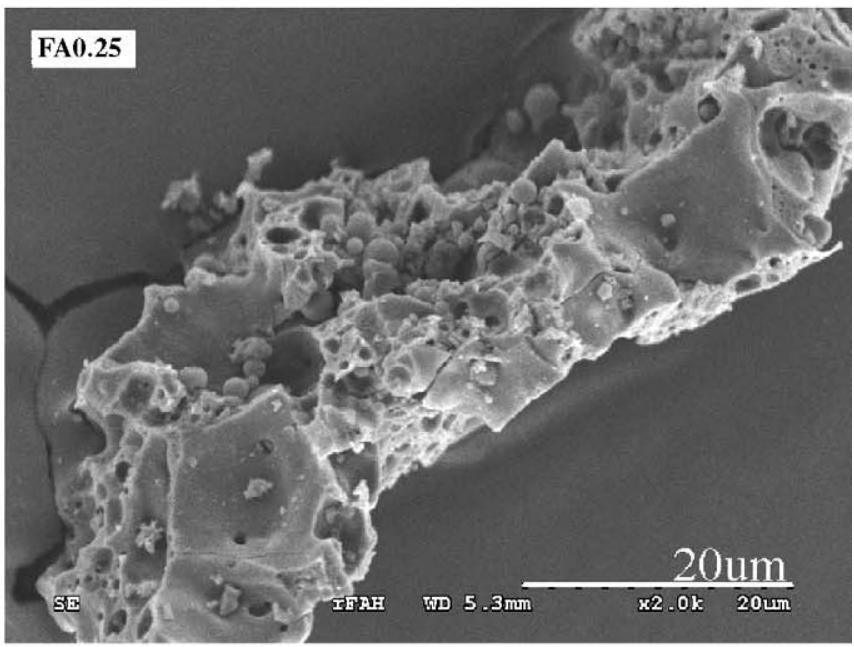

(d)

Fig. 5. SEM photographs of the red mud and fly ash samples before adsorption. (a) The SEM of raw red mud (RM). Accelerating voltage $=8 \mathrm{kV}$, magnification $=3000$. (b) The SEM of the RM treated with $0.25 \mathrm{~mol} / 1 \mathrm{HCl}$ for $2 \mathrm{~h}$ (RM0.25). Accelerating voltage $=8 \mathrm{kV}$, magnification $=4000$. (c) The SEM of raw fly ash (FA). Accelerating voltage $=8 \mathrm{kV}$, magnification $=1000$. (d) The SEM of the FA treated with $0.25 \mathrm{~mol} / 1 \mathrm{HCl}$ for $2 \mathrm{~h}(\mathrm{FA} 0.25)$. Accelerating voltage $=8 \mathrm{kV}$, magnification $=2000$.

ples exposed to $700^{\circ} \mathrm{C}$ still removed much phosphate than the raw materials (Fig. 4) even if the BET surface areas decreased. Although acidification enhanced the surface area of the samples (Table 2), precipitation of phosphate is weaken due to the calcite and some other metallic compounds dissolving during the acidified process (Fig. 2 and Fig. 3). Therefore, the change of BET surface area was not the only reason for the varieties of adsorbability, which indicated that the phosphate removal by the raw and activated materials was not only controlled by physical sorption, chemical interaction is also responsible for adsorption on sorbent surfaces.

\subsection{Effect of time on the removal of phosphate}

The effect of time on the removal of phosphate was made on the basis of the phosphate removal depending on contact time (Fig. 6). The time that the fly ash acquired to reach equilibrium was shorter than that of the red mud. The raw and activated materials had the similar trend of phosphate removal. After the initial rapid reaction, phosphate sorption continued to proceed at a slow rate and a true equilibrium was hardly reached within the time selected. Genç [27] reported that the equilibrium time previously used in batch experiments of arsenate removal from bauxsol coated sand was too short because adsorption continued for at least 21 days, but even after this time, a clear pseudo-equilibrium is not observed and it is not possible to determine whether this is the optimum adsorption density. Indeed, McConchie et al. [28] found that bauxsol increased its metal binding capacity in excess of 196 days. Consequently, the equilibrium mentioned in this study was a relative equilibrium. As seen from the figure, phosphate removal achieved the peak value in the first $4 \mathrm{~h}$, thus, $4 \mathrm{~h}$ was selected as a consistent time to investigate the effect of $\mathrm{pH}$ and initial phosphate concentration on the sorption capacity. 


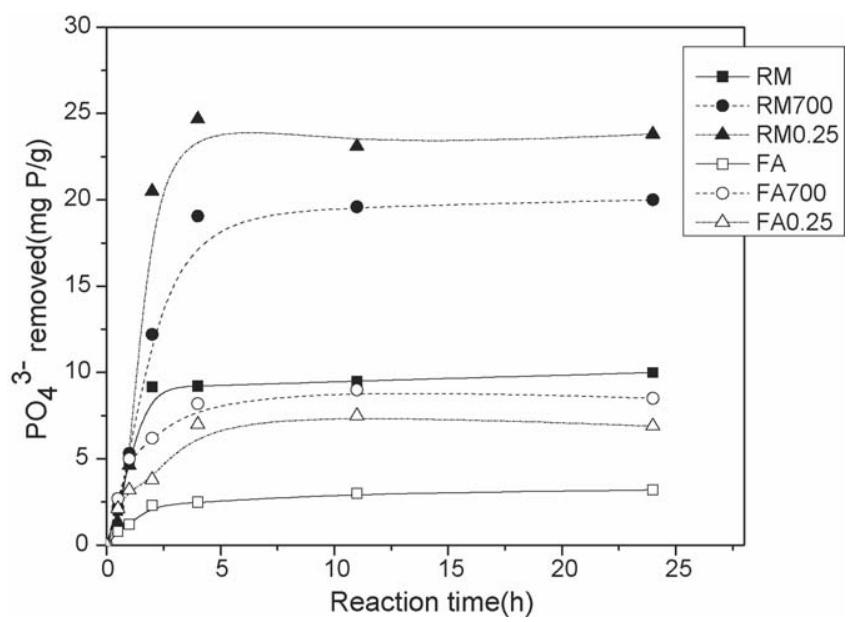

Fig. 6. Phosphate removal depending on contact time with the raw and activated red mud and fly ash $\left(C_{0}=155 \mathrm{mg} \mathrm{P} / 1,25^{\circ} \mathrm{C}\right)$.

\subsection{Effect of $p H$ on the removal of phosphate}

Fig. 7 showed the phosphate removal data at solution $\mathrm{pH} 1$, $3,5,7,9$ and 11 when the initial phosphate concentration was $155 \mathrm{mg}$ P/l. The phosphate removal of the samples reached maximum at $\mathrm{pH} 7$, after that the removal of phosphate decreased with the increase of $\mathrm{pH}$. A similar type of behavior is also reported for the adsorption of anionic species from aqueous solution on the activated red mud [29-30]. A ligand exchange mechanism took place in the sorption of phosphate onto the samples, and the sorption reaction may be written with the following ligand exchange reactions.

Surface hydrolysis reactions:

$$
\begin{aligned}
& \equiv \mathrm{SOH}+\mathrm{H}^{+}=\equiv \mathrm{SOH}_{2}{ }^{+} \\
& \equiv \mathrm{SOH}=\equiv \mathrm{SO}^{-}+\mathrm{H}^{+}
\end{aligned}
$$

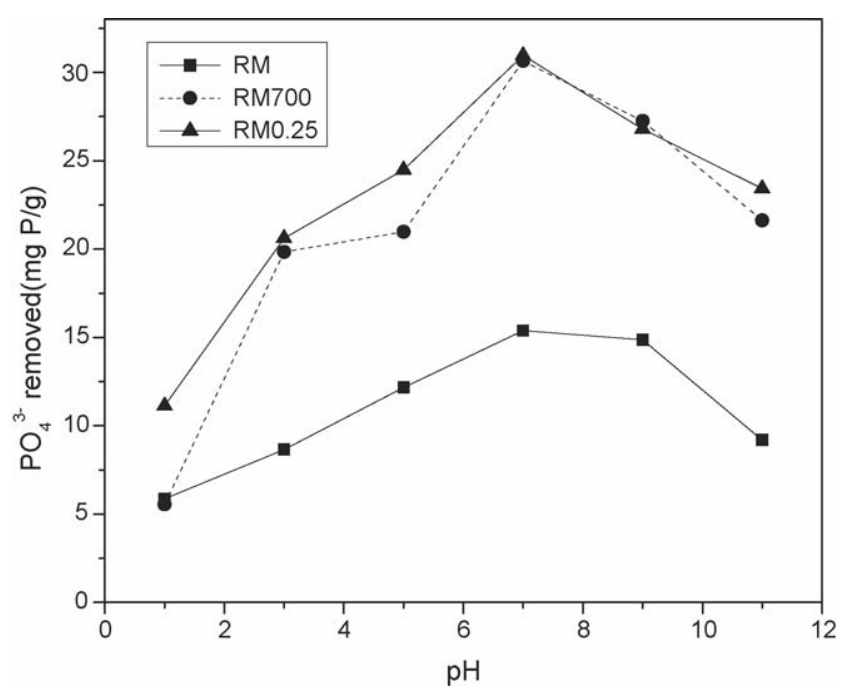

Fig. 7. Effect of $\mathrm{pH}$ on the phosphate removal by the raw and activated red mud $\left(C_{0}=155 \mathrm{mg} \mathrm{P} / 1,25^{\circ} \mathrm{C}\right)$.
Phosphate sorption reactions:

$$
\begin{aligned}
& \equiv \mathrm{SOH}+\mathrm{H}_{3} \mathrm{PO}_{4}=\equiv \mathrm{SH}_{2} \mathrm{PO}_{4}+\mathrm{H}_{2} \mathrm{O} \\
& \equiv \mathrm{SOH}+\mathrm{H}_{3} \mathrm{PO}_{4}=\equiv \mathrm{SHPO}_{4}{ }^{-}+\mathrm{H}^{+}+\mathrm{H}_{2} \mathrm{O} \\
& \equiv \mathrm{SOH}+\mathrm{H}_{3} \mathrm{PO}_{4}=\equiv \mathrm{SPO}_{4}{ }^{2-}+2 \mathrm{H}^{+}+\mathrm{H}_{2} \mathrm{O} \\
& \equiv \mathrm{SOH}+\mathrm{H}_{3} \mathrm{PO}_{4}=\equiv \mathrm{SOHPO}_{4}{ }^{3-}+3 \mathrm{H}^{+}
\end{aligned}
$$

Here $\equiv \mathrm{SOH}$ represents samples surface of the red mud and fly ash. When the $\mathrm{pH}$ increased at low $\mathrm{pH}$, the amount of $\mathrm{H}_{3} \mathrm{PO}_{4}$ is decreased and the acidic phosphates $\left(\mathrm{H}_{2} \mathrm{PO}_{4}{ }^{-}\right.$and $\mathrm{HPO}_{4}{ }^{2-}$ ) are the predominant aqueous species [31]. Since anion adsorption is coupled with a release of $\mathrm{OH}^{-}$ions, the adsorption is favored by low $\mathrm{pH}$ values. When the $\mathrm{pH}$ is increased beyond 7.0, a gradual decrease in the percentage of adsorption is observed which may be due to the competition between $\mathrm{OH}^{-}$and phosphate ions $\left(\mathrm{PO}_{4}{ }^{3-}\right)$. This kurtosis distribution of the phosphate removal dependent on $\mathrm{pH}$ was similar to the effect of $\mathrm{pH}$ on arsenic adsorption with activated neutralized red mud [29] for phosphate and arsenate often demonstrate a similar chemical behavior. Hexavalent chromium adsorption from aqueous solution by using activated red mud also had the similar dependent on $\mathrm{pH}$ [30]. The observed behavior of phosphate sorption with varying $\mathrm{pH}$ attributes to various mechanisms such as electrostatic attraction/repulsion, chemical interaction, and ion exchange which are responsible for adsorption on sorbent surfaces. The red mud is a complex mixture of different minerals, each with different point of zero surface charge (pHpzc) values. For example, the pHpzc value of hematite is 7.8, whereas the pHpzc of maghemite, gibbsite, boehmite, and quartz are 6.7, 5.0, 8.2, and 2.0-2.2, respectively [29,32]. These minerals can have different surface charges at a given $\mathrm{pH}$, and this gives red mud the capacity to remove phosphate over a wide $\mathrm{pH}$ range. In this experiment, the sorption capacities of RM700 and RM0.25 were significantly improved over broader $\mathrm{pH}$ range. It has been noted that higher phosphate removal occurred at the $\mathrm{pH}$ range of 5-9 for all samples than other $\mathrm{pH}$ scope. This may reflect the importance of hematite (pHpzc about 7.8) and maghemite (pHpzc about 6.7) in the sorption process. At $\mathrm{pH}$ 7, the phosphate removal by the RM, RM700 and RM0.25 was $15.40,30.67$ and $30.70 \mathrm{mg} \mathrm{P} / \mathrm{g}$, respectively, which was equal to $49.7,98.9$ and $99.0 \%$ phosphate removal efficiency. In this experiment condition, the phosphate remained in the supernatant liquid after sorption with RM700 and RM0.25 was 1.65 and $1.50 \mathrm{mg} \mathrm{P} / 1$, respectively. The results did not meet the $1.0 \mathrm{mg} \mathrm{P} / \mathrm{l}$ of phosphate effluent criterion, the maximum allowable loading for second-rate criterion required by Integrated Wastewater Discharge Standard [33]. As for the routine wastewater, the $155 \mathrm{mg} \mathrm{P} / 1$ initial phosphate concentration is not quite common, when the initial concentration is $15 \mathrm{mg} \mathrm{P} / 1$, phosphate was not determined after sorption for the sample of RM, RM700 and RM0.25 in this sorption condition mentioned above. The results even met the criterion for surface water environmental quality [33]. However, FA700 can only remove $73.5 \%$ phosphate, and the FA and FA0.25 removed less phosphate when the initial concentration was $155 \mathrm{mg} \mathrm{P} / 1$ and the solution $\mathrm{pH}$ was adjusted to 7.0. Thus the results indicated that this kind 
of fly ash used in this study was not suitable for phosphate removal.

\subsection{Sorption isotherms}

The effect of temperature on sorption was applied to different isotherm models to find the suitable model to instruct the further experimental design. The increase in phosphate sorption by red mud and fly ash samples with increasing temperature was analogous to the arsenate adsorption by activated red mud [29]. This trend indicated that chemisorption is taking place in the system. In order to compare the effect of initial phosphate concentrations on the phosphate removal with raw and treated red mud and fly ash samples, we discussed the sorption experiments carried out at $25^{\circ} \mathrm{C}$.

Several isotherm equations are available. In this study, the Langmuir and Freundlich isotherms have been selected. The Langmuir isotherm model assumes uniform energies of sorption onto the surface with no transmigration of adsorbate in the plane of the surface. The Freundlich isotherm model is an empirical equation employed to describe heterogeneous systems. The Langmuir and Freundlich isotherms can be presented by equations

$X=\frac{X_{\mathrm{m}} k C_{\mathrm{e}}}{1+k C_{\mathrm{e}}}$

$X=K_{\mathrm{F}} C_{\mathrm{e}}^{1 / n}$

respectively, where $X$ is equilibrium phosphate concentration on sorbent $(\mathrm{mg} / \mathrm{g}), X_{\mathrm{m}}$ is monolayer capacity of the sorbent $(\mathrm{mg} / \mathrm{g}), k$ is sorption constant $(1 / \mathrm{mg}), C_{\mathrm{e}}$ is equilibrium phosphate concentration in solution $(\mathrm{mg} / \mathrm{l}), K_{\mathrm{F}}$ and $n$ are the Freundlich exponent.

While the Langmuir isotherm parameters $X_{\mathrm{m}}$ and $k$ were obtained by plotting $1 / X$ versus $1 / C_{\mathrm{e}}$, the Freundlich isotherm parameters were obtained by plotting $\log X$ versus $\log C_{\mathrm{e}}$. The isotherm data were calculated from the least squares method.

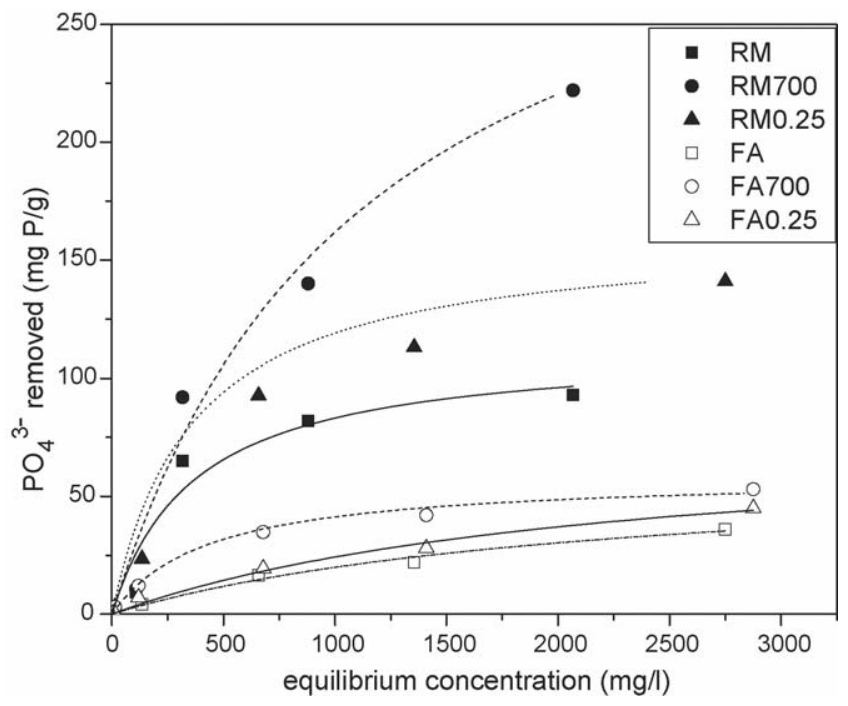

Fig. 8. Langmuir adsorption isotherm simulated the effect of initial concentration on phosphate removal using RM and FA with different activated treatment.

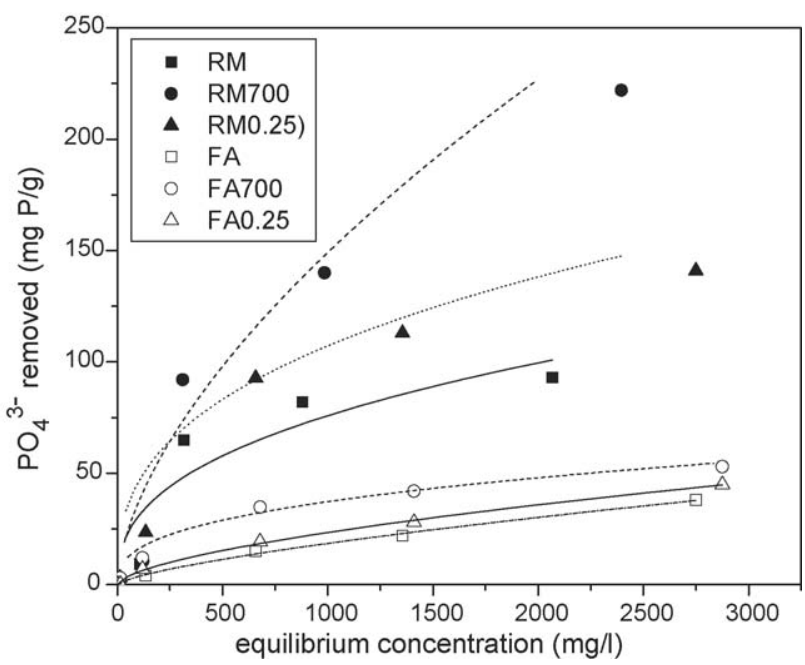

Fig. 9. Freundlich adsorption isotherm simulated the effect of initial concentration on phosphate removal using RM and FA with different activated treatment.

Figs. 8 and 9 showed a plot of the phosphate loading on the sorbent against the phosphate equilibrium concentration in the liquid phase. The symbols in the figures expressed the data obtained in experiment, and the lines stood for the isotherms simulated the experiment data. The results of this study showed that phosphate uptake increased with the equilibrium phosphate concentration for each sorbent.

The values of the parameters of the two models and the related correlation coefficients $\left(R^{2}\right.$ values) were listed in Table 3 . The results showed that the Langmuir equation better fitted the sorption equilibrium data over the concentration range used in this investigation than the Freundlich equation did, which was not in agreement with the findings of Wang et al. [12]. The diversity attributed to the different characteristics of the raw materials and the different treatment methods. It was clear from Table 3 that the values of $X_{\mathrm{m}}$ for RM700 and the values of $K_{\mathrm{F}}$ for RM0.25

Table 3

Comparison of Langmuir and Freundlich adsorption isotherm models

\begin{tabular}{llll}
\hline Model & \multicolumn{2}{l}{ Parameters } & $R^{2}$ \\
\cline { 2 - 3 } & $X_{\mathrm{m}}(\mathrm{mg} / \mathrm{g})$ & $k(1 / \mathrm{mg})$ & \\
\hline Langmuir isotherm & & & \\
RM & 113.870 & 0.00271 & 0.957 \\
RM700 & 345.501 & 0.00088 & 0.985 \\
RM0.25 & 161.614 & 0.003 & 0.970 \\
FA & 63.219 & 0.00046 & 0.992 \\
FA700 & 58.924 & 0.002 & 0.992 \\
FA0.25 & 78.441 & 0.00045 & 0.991 \\
& & & \\
Model & Parameters & & \\
\cline { 2 - 3 } & & & \\
& & & \\
\hline Freundlich isotherm $(\mathrm{mg} / \mathrm{g})$ & & & \\
RM & 5.051 & 0.392 & 0.835 \\
RM700 & 2.272 & 0.606 & 0.954 \\
RM0.25 & 8.546 & 0.366 & 0.828 \\
FA & 0.142 & 0.705 & 0.998 \\
FA700 & 2.990 & 0.365 & 0.965 \\
FA0.25 & 0.336 & 0.614 & 0.997 \\
\hline
\end{tabular}


were higher in comparison to other materials. Thus, the sorption capacity for RM700 and RM0.25 was greater than other samples. According to our experiments mentioned above, both the RM0.25 and RM700 could remove about $99 \%$ phosphate from the solution when the initial phosphate was $155 \mathrm{mg} \mathrm{P} / 1$.

\section{Conclusions}

Since the RM and FA are waste, fine grained and inexpensive they can be economically used for the removal of phosphate from wastewater. The uptake of phosphate by the RM and FA thermally activated at various temperatures and acid activated at various $\mathrm{HCl}$ concentrations was investigated by a batch method. The sorption capacity can be enhanced by activation. The RM0.25 and RM700 obtained the optimal removal of $\mathrm{PO}_{4}{ }^{3-}$. For the fly ash, the sample FA700 was better than other fly ash samples. The phosphate removal was also influenced by solution $\mathrm{pH}$. At $\mathrm{pH} 7$, the RM0.25 and RM700 can remove almost $99 \%$ phosphate from solution with the $155 \mathrm{mg} \mathrm{P} / \mathrm{l}$ initial phosphate concentration. We prefer the RM0.25 and RM700 to the other materials because of their stable high sorption capacity over broader $\mathrm{pH}$ applicability to phosphate sorption. They appear to be extremely suitable for reducing phosphate from industrial effluents like those of phosphatic fertilizer plants. Correlation coefficients indicate that the Langmuir isotherm model was applied more effectively than the Freundlich model to phosphate sorption onto the red mud and fly ash, which consist of a heterogeneous mixture of several minerals.

\section{Acknowledgements}

This work was supported by the National Natural Science Foundation of China (No. 40273044). The authors thank Mr. Wencheng Li from Research Institute of Shandong Aluminium Co. Ltd., for providing the raw red mud and fly ash. We also thank Emma Snyder from Foreign Languages Department of Graduate School of China Academy of Sciences for her revision of the language. Thanks are due to the editors and anonymous reviewers for their helpful suggestions and enlightening comments.

\section{References}

[1] A. Ugurlu, B. Salman, Phosphorus removal by fly ash, Environ. Int. 24 (8) (1998) 911-918.

[2] G. Crini, Non-conventional low-cost adsorbents for dye removal: a review, Bioresource. Technol., in press, corrected proof, available online 29 June 2005

[3] E. Galarneau, R. Gehr, Phosphorus removal from wastewaters: experimental and theoretical support for alternative mechanisms, Water Res. 31 (2) (1997) 328-338.

[4] S.J. Shiao, K. Akashi, Phosphate removal from aqueous solution from activated red mud, J. WPCF 49 (2) (1977) 280-285.

[5] E. López, B. Soto, M. Arias, A. Núñez, D. Rubinos, T. Barral, Adsorbent properties of red mud and its use for wastewater treatment, Water Res. 32 (4) (1998) 1314-1322.

[6] J. Pradhan, J. Das, S.N. Das, R.S. Thakur, Adsorption of phosphate from aqueous solution using activated red mud, J. Colloid Interface Sci. 204 (1998) 169-172.
[7] E. Oguz, Sorption of phosphate from solid/liquid interface by fly ash, Colloids Surf. A: Physicochem. Eng. Aspects 262 (1-3) (2005) 113-117.

[8] N.M. Agyei, C.A. Strydom, J.H. Potgieter, An investigation of phosphate ion adsorption from aqueous solution by fly ash and slag, Cem. Concr. Res. 30 (2000) 823-826.

[9] N.M. Agyei, C.A. Strydom, J.H. Potgieter, The removal of phosphate ions from aqueous solution by fly ash, slag, ordinary Portland cement and related blends, Cem. Concr. Res. 32 (12) (2002) 1889-1897.

[10] Y. Çengeloğlu, E. Kır, M. Ersöz, Removal of fluoride from aqueous solution by using red mud, Sep. Purif. Technol. 28 (2002) 81-86.

[11] M. Erdem, H.S. Altundoğan, F. Tümen, Removal of hexavalent chromium by using heat-activated bauxite, Miner. Eng. 17 (9-10) (2004) $1045-1052$

[12] S. Wang, Y. Boyjoo, A. Choueib, Z.H. Zhu, Removal of dyes from aqueous solution using fly ash and red mud, Water Res. 39 (1) (2005) 129-138.

[13] H.S. Altundoğan, F. Tümen, Removal of phosphates from aqueous solutions by using bauxite. II. The activation study, J. Chem. Technol. Biotechnol. 78 (2003) 824-833.

[14] H.S. Altundoğan, F. Tümen, Removal of phosphates from aqueous solutions by using bauxite. I. Effect of $\mathrm{pH}$ on the adsorption of various phosphates, J. Chem. Technol. Biotechnol. 77 (2002) 77-85.

[15] H. Genç, J.C. Tjell, D. McConchie, O. Schuiling, Adsorption of arsenate from water using neutralized red mud, J. Colloid Interface Sci. 264 (2) (2003) 327-334.

[16] H. Genç-Fuhrman, J.C. Tjell, D. McConchie, Increasing the arsenate adsorption capacity of neutralized red mud (Bauxsol), J. Colloid Interface Sci. 271 (2) (2004) 313-320.

[17] R. Piekos, S. Paslawska, Fluoride uptake characteristics of fly ash, Fluoride 32 (1) (1999) 14-19.

[18] H. Nollet, M. Roels, P. Lutgen, P. Van der Meeren, W. Verstraete, Removal of PCBs from wastewater using fly ash, Chemosphere 53 (2003) 655-665.

[19] M. Erol, S. Küçükbayrak, A. Ersoy-Meriçboyu, T. Ulubaş, Removal of $\mathrm{Cu}^{2+}$ and $\mathrm{Pb}^{2+}$ in aqueous solutions by fly ash, Energy Convers. Manage. 46 (7-8) (2005) 1319-1331.

[20] P.C. Kao, J.H. Tzeng, T.L. Huang, Removal of chlorophenols from aqueous solution by fly ash, J. Hazard. Mater. 76 (2-3) (2000) 237-249.

[21] A. Baba, A. Kaya, Leaching characteristics of solid wastes from thermal power plants of western Turkey and comparison of toxicity methodologies, J. Environ. Manage. 73 (3) (2004) 199-207.

[22] P. Bankowski, L. Zou, R. Hodges, Using inorganic polymer to reduce leach rates of metals from brown coal fly ash, Miner. Eng. 17 (2) (2004) 159-166.

[23] T.S. Singh, K.K. Pant, Solidification/stabilization of arsenic containing solid wastes using portland cement, fly ash and polymeric materials, J. Hazard. Mater., in press, corrected proof, available online 2 November 2005.

[24] H. Genç, J.C. Tjell, Effects of phosphate, silicate, sulphate and bicarbonate on arsenate removal using seawater-neutralized red mud (Bauxsol), J. Phys. IV 107 (2003) 537-540.

[25] E. Arnold, Standard Methods for the Examination of Water and Wastewater, 16th ed., American Public Health Association, Washington, DC, New York, 1985, pp. 445-446.

[26] R.M. Cornell, U. Schwertmann, The Iron Oxide Structure, Properties, Reactions Occurrence and Uses, VCH Publishers, New York, 1996, p. 573.

[27] H. Genç-Fuhrman, H. Bregnhøj, D. McConchie, Arsenate removal from water using sand-red mud columns, Water Res. 39 (13) (2005) 2944-2954.

[28] D. McConchie, M. Clark, C. Hanahan, R. Fawkes, The use of seawaterneutralised bauxite refinery residues (red mud) in environmental remediation programs, in: I. Gaballah, J. Hager, R. Solozabal (Eds.), Proceedings of the 1999 Global Symposium on Recycling, Waste Treatment and Clean Technology, San Sebastian, Spain, 1999.

[29] H. Genç-Fuhrman, J.C. Tjell, D. McConchie, Adsorption of arsenic from water using activated neutralized red mud, Environ. Sci. Technol. 38 (8) (2004) 2428-2434. 
[30] J. Pradhan, S. Das, R.S. Thakur, Adsorption of hexavalent chromium from aqueous solution by using activated red mud, J. Colloid Interface Sci. 217 (1999) 137-141.

[31] W. Stumm, J.J. Morgan, Aquatic Chemistry, third ed., Wiley, New York, 1996, p. 780.
[32] W. Stumm, Chemistry of the Solid Water Interface, Wiley \& Sons, New York, 1992, p. 448.

[33] China Bureau of Environmental Protection, Water and Wastewater Monitor and Analysis Method, third ed., China Environmental Science Press, Beijing, 1997, p. 610, in Chinese. 